\title{
Brian Patrick Kavanagh, MB, BCh, BAO, BSc, MRCP(I), FRCPC
}

\author{
Sam D. Shemie, MD • Colin J. L. McCartney, MBChB, PhD, FRCPC ( \\ C. David Mazer, MD, FRCPC
}

Received: 28 August 2019/Revised: 31 August 2019/Accepted: 1 September 2019/Published online: 16 September 2019 (C) Canadian Anesthesiologists' Society 2019

"Don't judge each day by the harvest you reap, but by the seeds that you sow" R.L. Stevenson

In June this year, the Canadian anesthesia and critical care community lost one of its outstanding leaders. Professor Brian Kavanagh was a respected leader in Canadian medicine; a caring and gifted physician, a highly regarded teacher, a talented scientist, a generous mentor, and a good friend.

Brian was born and raised in Dublin, where he developed a love of music, Irish literature, and the power of humour. After graduating from the National University of Ireland medical school he completed training in internal medicine and in 1989 immigrated with his family to Toronto. Following an anesthesia residency at the University of Toronto he completed fellowships in cardiac anesthesia at Toronto General Hospital and Critical Care Medicine at Stanford University Medical Center before being appointed to the staff of Toronto General Hospital in 1995. In 1999, he moved to the Hospital for Sick Children as a staff physician in critical care medicine and anesthesia, and in 2003 was named to the Geoffrey Barker Chair in Critical Care Medicine. He served two terms as chair of the Department of Anesthesia at the University of Toronto from 2006 to 2017, continuing the work that has made the department one of the preeminent academic departments of anesthesia in the world. He was the long-standing chair of the Critical Care Canada

\footnotetext{
S. D. Shemie, MD

Division of Critical Care, Montreal Children's Hospital, McGill University, Montreal, QC, Canada
}

\section{J. L. McCartney, MBChB, PhD, FRCPC ( $\triangleleft)$}

Department of Anesthesiology and Pain Medicine, University of Ottawa, Ottawa, ON, Canada

e-mail: cmccartney@toh.ca

C. D. Mazer, MD, FRCPC

Department of Anesthesia and Physiology, University of Toronto, Toronto, ON, Canada
Forum, an associate editor of the journal Critical Care, and an executive editor of the journal Anesthesiology. At the same time, he developed an outstanding laboratory at the Hospital for Sick Children, studying the mechanisms of ventilator-associated lung injury and the impact of carbon dioxide in the lung. His research was innovative, widely cited, and very impactful, as evidenced by an impressive record of continuous peer-reviewed funding and hundreds of publications in top-level journals.

Brian was a deeply private person, but he always found time to give to others. In many ways he was the perfect mentor-deeply passionate about academic medicine, a respected international leader with his own excellence in research and clinical practice, always finding time to be supportive in discussions and optimistic about potential for new challenges, and innovative in stretching people to greater heights than they themselves thought possible. The instructions to residents heading to the Hospital for Sick Children for critical care training was clear- "just follow Brian around". He pushed us all to do better and to try harder, often leading tough conversations about putting the patient and academic mission as our priorities. Although some found this challenging, more found it inspiring, and this surely contributed to attracting outstanding candidates wanting to train in anesthesiology and critical care. Indeed, Brian trained (Fig. 1) and mentored many people over his career and, not surprisingly, many of them have gone on to develop their own world-leading programs across Canada and the world.

Brian's clarity of thought, speech, and brilliance were well-known and widely appreciated. Deeply intelligent with a quick wit, he was a true original thinker who encouraged similar original thinking in others. He was so exceptionally articulate that he could be both encouraging and provocative with the same comment. This also made him one of the finest pro-con academic debaters internationally. He was also known for some rather colourful language, sometimes better suited to a pub in Dublin than during rounds. Nevertheless, he learned to 
Fig. 1 Brian in "full flow" during rounds at the Hospital for Sick Children in Toronto
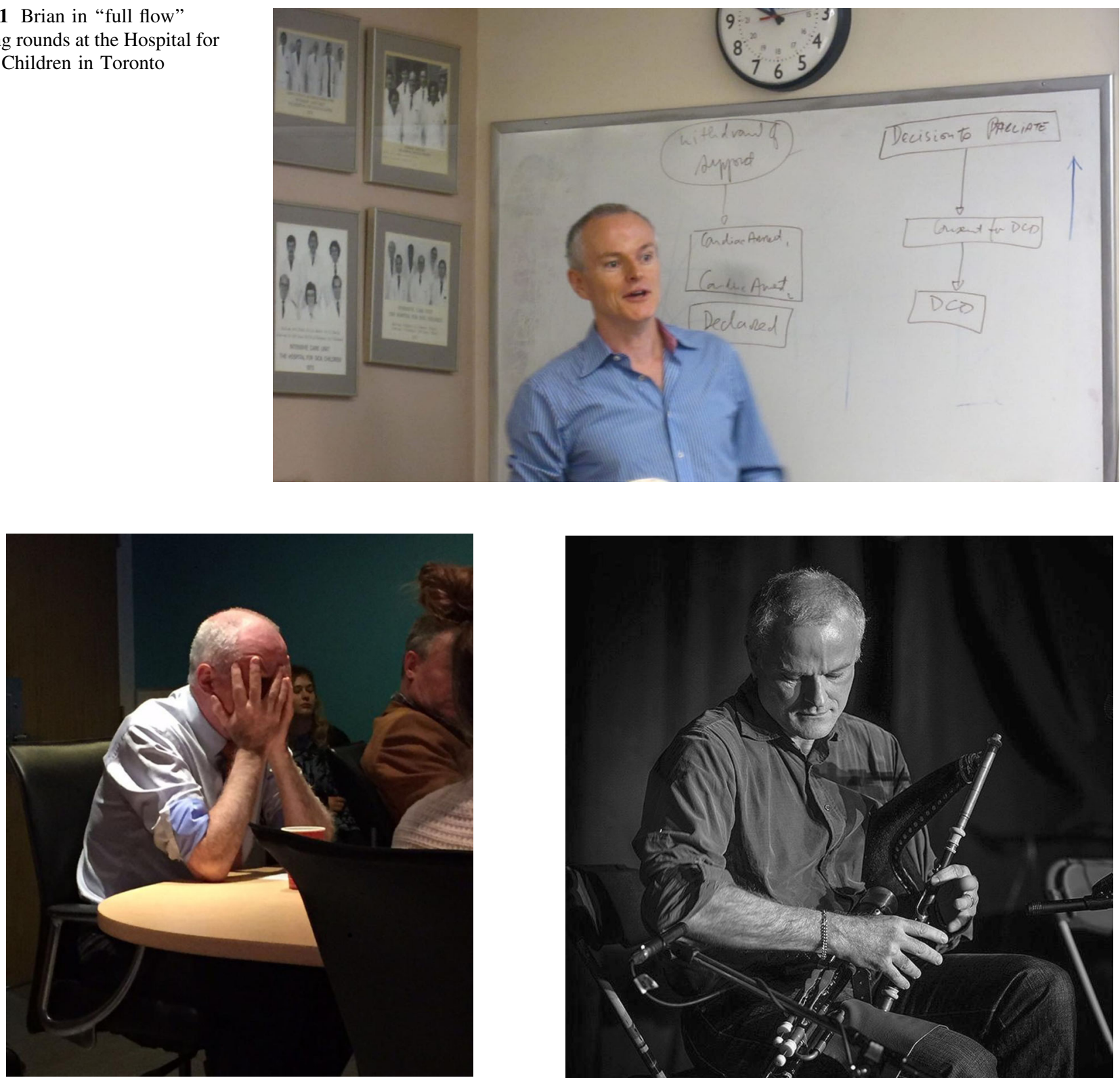

Fig. 2 The Kavanagh "hands over the face" gesture

temper the colourful language while transmitting the intended message with non-verbal cues, such as the now famous "hands over the face" gesture (Fig. 2), the meaning of which is clearly apparent to those who knew him.

Brian also was known for many notable quotations, eloquently stating that "Research is not about being smart, it's about realizing that you are ignorant". He also memorably quipped that "there are only three gaps-the osmolar gap, anion gap, and the knowledge gap". During a pro-con debate at the Critical Care Canada Forum with an internationally renowned intensivist/bioethicist, Brian made a particularly provocative comment, and his bioethicist debate adversary, in an attempt to urge

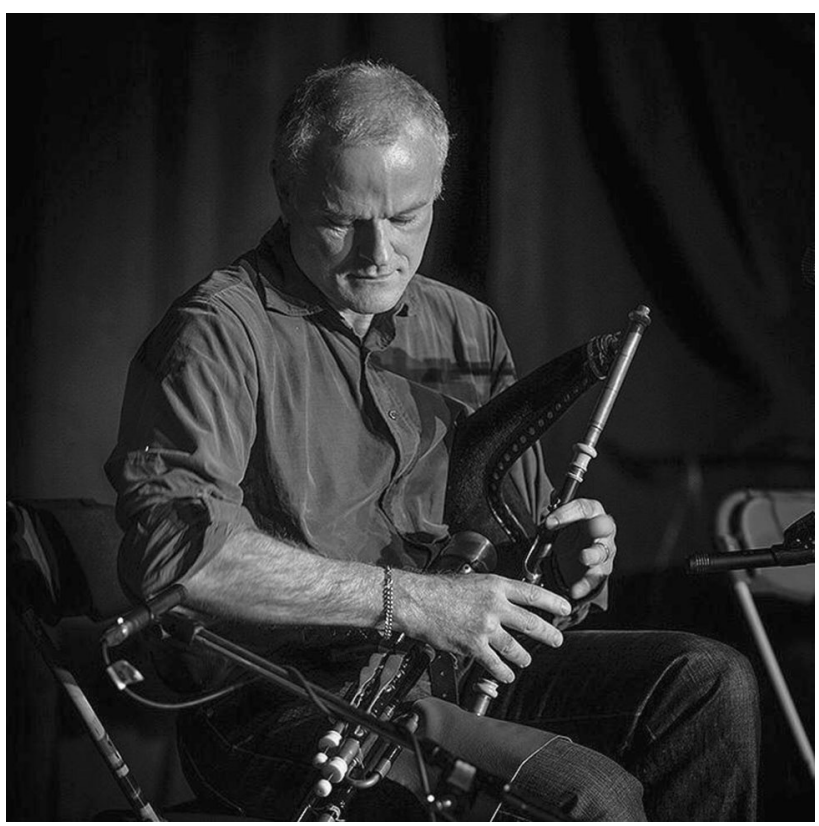

Fig. 3 While Brian was very modest about his non-academic talents, he was a very skilled Irish Uilleann piper and flute player, performing in sessions around Toronto

reflection, said "OK, let's think about that" to which Brian responded, "I did". He objected to the "tyranny" of group-think and protocols/guidelines, and fervently advocated for individuality and original thinking in medicine. He was well-known for penetrating hard scientific truths stating that "consensus means you don't know, because if you knew, you wouldn't need consensus".

Brian did not discuss his health, and his sudden death came as a shock to many people. He was active right up until his final illness, including playing a key role in the 
process to advance the vision for Canadian anesthesiology research at the meeting of the Perioperative Anesthesia Clinical Trials meeting held in February 2019. Many of his colleagues, mentees, and friends did not know he was unwell and missed an opportunity to let him know how much they valued his friendship, mentorship, and support. There was an overwhelming outpouring of love and respect from around the world in the memorial pages after his death. It is a bitter irony that in the month that he died, he was awarded a Tier 1 Canada Research Chair in acute lung injury. He managed to achieve this in the face of a terminal illness. His dire circumstances did not matter to him-he was revising his curriculum vitae and advising his research fellows the night before he died.

The outpouring of grief and tribute for Brian was a testament to his quality as a person and his impact on others- "An inviolable international treasure"; "the pure definition of excellence and careful precision"; "the guiding beam of light"; "the mentor of mentors"; "the absolute insightful gentleman". Brian would no doubt be scientifically disappointed with the overwhelming conclusion that both in Canada and internationally, the evidence-informed "consensus" is that he was a great man who helped to advance the way we care, and inform the care, for patients in anesthesiology, critical care, and pain medicine.

Conflicts of interest None declared.

Editorial responsibility This submission was handled by Dr. Hilary P. Grocott, Editor-in-Chief, Canadian Journal of Anesthesia.

Publisher's Note Springer Nature remains neutral with regard to jurisdictional claims in published maps and institutional affiliations. 